\section{BUTYL ALCOHOL AS A MEDIUM FOR THE DETERMINA- TION OF SAPONIFICATION NUMBERS ${ }^{1}$}

By A. M. Pardee, R. L. Hasche and E. Emmet Reid

Chemrcal, Laboratories, Washington and JefFerson College, WashINGTON, PA., AND JOHNS HOPEINS UNIVERSITY, BALTIMORE, MD.

Received October 7, 1919

In a recent article ${ }^{2}$ it was shown that normal butyl alcohol is an excellent medium in which to conduct the quantitative saponification of esters. This suggested its use in the determination of the saponification numbers of fixed oils, fats, and waxes. The method of Koettstorfer ${ }^{8}$ has, with little modification, been generally adopted." That difficulties are met with is shown by the number of modifications that have been proposed. The chief trouble has been in getting some of the fats and waxes into perfect solution in the ethyl alcoholic potash.

Smithan ${ }^{5}$ adds $20 \mathrm{cc}$. of ether, and Heniriques ${ }^{6}$ uses petroleum ether to aid solution in his cold saponification method.

Lewkowitsch ${ }^{7}$ advises heating fats which are difficult to saponify under pressure, using copper bottles with screw caps.

Kossel and Obremueller treat the sample with absolute alcohol in which metallic sodium has been dissolved.

Wool fat has given much trouble. Lewkowitsch says "wool wax must be boiled with an excess of $0.5 \mathrm{~N}$ alcoholic potash for a least 24 hrs." Fabrion ${ }^{8}$ has completely saponified it in an open capsule, on the water bath, with $2 N$ caustic soda, repeatedly boiling it almost to dryness to get rid of the water, and taking up the residue each time with strong alcohol.

Winkler ${ }^{9}$ recommended the use of propyl alcohol, since it is a better solvent for fats and has a higher boiling point. He tried twelve oils, fats, and waxes, and obtained good results.

Normal butyl alcohol, boiling at a higher temperature than either ethyl or propyl alcohol, makes possible the use of higher temperatures for the saponification. Its longer hydrocarbon chain increases its solvent power for fats, waxes, etc. From the work of Anderson and Pierce ${ }^{10}$ it appears that at $25^{\circ}$ the saponification velocities of an acetate in methyl, ethyl, and isoamyl alcohols are in the ratio $\mathrm{I}: 7:$ I 5 . From this saponification might be expected to proceed much more rapidly in normal butyl than in ethyl alcohol.

The simple method of Koettstorfer gives excellent results for the more common oils and fats and, by various modifications, special cases can be taken care of, but it is desirable to have a simple method which will be applicable to a wide variety of materials with-

1 Our thanks are due to Dr. G. S. Jamieson, in charge of Oil, Fat, and Wax Iaboratory, U. S. Bureal of Chemistry, for several helpful criticisms. The experimental work was carried out at Washington and-Jefferson College by A. M. Pardee and R. I. Hasche.

2 TaIs Journat, $12(1920), 129$.

B Z. anal. Chem., 18 (1879), 199.

4 Official and Provisional Methods of Analysis, U. S. Dept. of Agr., Bulletin 107 (1911), 137; ThIs JOURNAL, 11 (1919), 1165.

Analyst, 18 (1893), 193.

- $Z$. angere. Chem., 1895, 721 .

" "Chemical Technology of Oils, Fats and Waxes"" 1 (1909), 85.

8 . angere. Chem., 1898, 268 .

I Ibid., 24: (1911), 636.

10 J. Phys. Chem., 22 (1918), 51. out extra precautions. The official directions read "boil for $30 \mathrm{~min}$. or until the fat is completely saponified." The operator is thus required to observe and to decide when the "fat is completely saponified," since much longer time is required for some fats than for others.

The plan of the present study was to put a number of fats, oils, and waxes through identically the same treatment, making the manipulation as simple as possible in the hope of finding a simple routine method with wide application. For comparison, runs were made using ethyl alcoholic soda in the same volume as when butyl alcohol was used. It is the common practice to use considerably larger proportions of ethyl alcohol than this, so as to effect complete solution, and thereby excellent results are obtained. The comparison is simply between butyl and ethyl alcohol under these special conditions.

\section{MATERIALS}

The ethyl alcohol for making the standard solution was purified by treating with caustic potash and silver nitrate, and distilling. The normal butyl alcohol was used as obtained in the market. In each case, the alcoholic alkali was prepared by adding metallic sodium to the alcohol. The oils, fats, and waxes were the best commercial samples obtainable, rancid and discolored specimens being rejected. Those which appeared to contain water were dried at II $0^{\circ}$. They were selected according to the groups given in Allen's "Commercial Organic Analysis."

\section{EXPERIMENTAI PROCEDURE}

One-gram samples were taken. The fats were weighed into roo-cc. round bottom Jena flasks, five of which, making a series, were fastened to a rack so that they could be lowered and raised simultaneously. They fitted into five openings in a steam bath and were provided with $3 \mathrm{ft}$. air condensers.

The oils were weighed into the saponification flasks from small Erlenmeyer flasks fitted with dropping pipettes. The waxes were cut into small cubes, while the butter, wool fat, and lanolin were weighed in small glass capsules.

To the material in the flask were added Io cc. of the standard $0.5 N$ alcoholic alkali. The flask was placed immediately on the steam bath and heated exactly one hour when it was removed, $50 \mathrm{cc}$. carbon dioxidefree water added, and the excess alkali titrated with $0.5 \mathrm{~N}$ hydrochloric acid. In case the unsaponified material was high melting the mixture was kept hot during the titration.

As the butyl alcohol was nearly anhydrous, $0.5 \mathrm{cc}$. of water was added to each flask containing this alcohol, half an hour after the heating had begun, to provide for the saponification of the butyl ester, the formation of which is the first thing that takes place.

\section{RESULTS}

The results are given below in tables, the figures in each line representing simultaneous experiments. " $E$ " designates the series in ethyl alcohol and " $B$ " those in normal butyl alcohol. Under "Difference" is placed the percentage by which the average of the ethyl al- 
cohol figures falls short of the butyl. Since it has been customary to give saponification numbers in terms of $\mathrm{KOH}$, the results obtained with the sodium alcoholates have been calculated to this basis and are so put down in the tables.

Tabie I-Saponification Numbers in EThyl, and Butru Alcohols

\begin{tabular}{|c|c|c|c|c|c|c|c|}
\hline & & OIL & & & & $\begin{array}{l}\text { AV- } \\
\text { ER- } \\
\text { AGE }\end{array}$ & $\begin{array}{l}\text { PER- } \\
\text { CENT- } \\
\text { AGE } \\
\text { DIF- } \\
\text { FER- } \\
\text { ENCE }\end{array}$ \\
\hline stor........ & $\begin{array}{l}180.0 \\
179.1\end{array}$ & $\begin{array}{l}180.6 \\
181.5\end{array}$ & $\begin{array}{l}180.7 \\
181.9\end{array}$ & 80.2 & $\begin{array}{l}179.9 \\
181.5\end{array}$ & $\begin{array}{l}180.3 \\
181.2\end{array}$ & 1.5 \\
\hline Cocont & $\begin{array}{l}247.1 \\
250.0\end{array}$ & $\begin{array}{l}248.7 \\
249.6\end{array}$ & $\begin{array}{l}249.1 \\
249.8\end{array}$ & 250.8 & 248.3 & 250.0 & \\
\hline od-liver. & $\begin{array}{l}179.7 \\
191.0\end{array}$ & & & & $\begin{array}{l}178.9 \\
190.4\end{array}$ & $\begin{array}{l}179.1 \\
190.5\end{array}$ & \\
\hline attonse & & & & & 193.5 & & 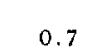 \\
\hline roton... & & & & & & & 8. \\
\hline inseed. & & & & & & & \\
\hline Teat's fo & & & & & 114.1 & .5 & 15. \\
\hline & & & & & 204.4 & $\begin{array}{l}197.2 \\
205.2\end{array}$ & \\
\hline Peach Kerne & $\begin{array}{l}189.9 \\
191.1\end{array}$ & & & & 189.7 & & \\
\hline Rape See & & & & & $\begin{array}{l}168.3 \\
174.5\end{array}$ & & $\pi$ \\
\hline Sosa & & & & & 191.6 & & \\
\hline 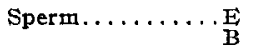 & & & & & $\begin{array}{l}134.1 \\
148.7\end{array}$ & & \\
\hline Sperm, adulter & & & & & $\begin{array}{l}139.0 \\
151.3\end{array}$ & & \\
\hline & & & & & & & \\
\hline Beeswax, & & & & & $\begin{array}{l}76.9 \\
97.2\end{array}$ & & \\
\hline permaceti......E & & & & 5.3 & 126.2 & & \\
\hline 急 & & & & & 228.6 & & \\
\hline & & & & & 219.0 & & \\
\hline allow............ & $\begin{array}{l}185.8 \\
197.1\end{array}$ & & $\begin{array}{l}181.8 \\
199.0\end{array}$ & & 183.6 & & \\
\hline $\begin{array}{l}\text { Wool Fat, Anhy- } \\
\text { drous.......... }\end{array}$ & & & & & 113. & & $a^{-1}$ \\
\hline 焉 & $\begin{array}{l}56.4 \\
70.0 \\
76.5 \\
84.7 \\
95.6\end{array}$ & $\begin{array}{l}51.0 \\
70.5 \\
74.6 \\
77.7 \\
95.6\end{array}$ & $\begin{array}{l}48.3 \\
70.6 \\
77.3 \\
84.3 \\
95.4 \\
67.7 \\
82.4\end{array}$ & $\begin{array}{r}49.1 \\
70.7 \\
76.4 \\
84.5 \\
99.5 \\
66.9 \\
78.6\end{array}$ & $\begin{array}{l}48.1 \\
735.2 \\
07\end{array}$ & $\begin{array}{l}50.6 \\
70.4 \\
76.0 \\
83.8 \\
96.8 \\
65.5 \\
80.0\end{array}$ & 3. \\
\hline
\end{tabular}
1 With absolute alcohol and sodium, according to Allen's "Commercial Analysis," II, 495 .

It appears from these runs that substantially the same values are obtained in ethyl and butyl alcohols for the more readily saponified oils and fats, though the values in butyl alcohol are always somewhat higher. For substances that are more difficult to sapơnify, considerably higher and more reliable values are obtained in butyl alcohol than in the same volume of ethyl alcohol. Doubtless the ethyl alcohol values would have come up to the higher figures had larger amounts of alcohol been employed, or had the heating been continued till complete saponification had been effected. The figures obtained in butyl alcohol agree well with the accepted values. Our sample of neat'sfoot oil must have been adulterated. The low results with tallow in ethyl alcohol are surprising. They were repeated with a different sample of tallow which gave higher fgures but those for the two alcohols were in the same ratio.
In order to get some idea of relative rates of saponification in the two solvents, the following experiments were run. The procedure was exactly as in the foregoing except that the flasks were removed at the intervals noted.

TABLF II-RELATIVE RATES OF SAPONIFICATION IN ETHYL AND BuTYL

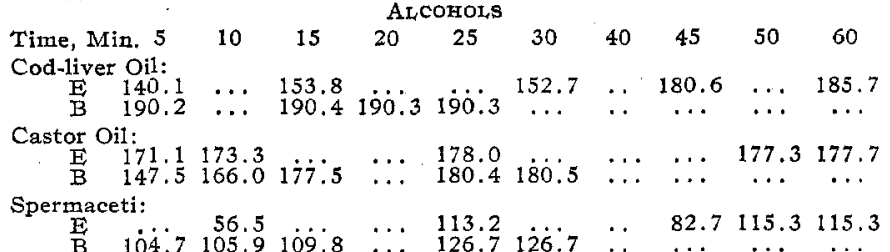

It appears from these results that the saponification of cod-liver oil is complete in $5 \mathrm{~min}$. in normal butyl alcohol but requires considerably more time in ethyl. Castor oil is saponified rapidly in both, while spermaceti is acted on less rapidly in both but much more rapidly in butyl than in ethyl.

\section{CONCLUSTON}

Normal butyl alcohol is found to be superior to ethyl as a medium for quantitative saponification, as by its use satisfactory results are more readily obtained and special precautions are less often required.

\section{A NEW METHOD FOR THE DETERMINATION OF SULFUR IN OILS ${ }^{1}$ \\ By C. E. Waters}

Bureau of Standards, Washington, D. C. Received November 6, 1919

It is well known that crude petroleum from whatever source contains more or less sulfur in combination. The lubricating oils and other products obtained from the crude oil must also contain sulfur unless special methods of refining are applied. In addition to their original sulfur content, the oils may be contaminated by sulfonic acids ${ }^{2}$ which are formed when the oils are treated with concentrated sulfuric acid during refining, and are not afterwards completely washed out.

Little is known about the relation between the sulfur content and certain of the properties of oils. The chiet reason for this may be the inconvenience, if not also the inaccuracy, of nearly every method that has been suggested for the determination of this element. Specifications have little to say about it. A limiting value may be set for fuel oils on account of the corrosive effect of the products of combustion. Transformer oils must contain a minimum amount. The test with polished copper, which is frequently called for, may be regarded as a demand for a low content of sulfur, be-

1 Published by permission of the Director of the Bureau of Standards.

: Although spoken of as sulfonic acids, it is certain that they are, at least in part, the acid esters of sulfuric acid and, therefore, analogous to ethyl sulfuric acid. The true sulfonic acids cannot be hydrolyzed by digestion with mineral acids, but this action takes place readily with the esters, and the sulfuric acid is recovered. When true sulfonic acids, e. g., benzenesulfonic acid, is broken down by regulated fusion with caustic alkali, the sulfite of the metal is formed. A heavy red oil (from $F$. $R$. Baxter, Vacuum Oil Co.), known to contain "sulfonic acids," gave no reaction for sulfuric acid when digested with water, but a slight reaction when so treated with $1: 1$ hydrochloric acid. When sealed up with concentrated hydrochloric acid and heated inside a steam bath, it gave a strong reaction for stulfuric acid. 